\title{
Crescimento e produtividade do girassol cultivado na entressafra com diferentes lâminas de água ${ }^{1}$
}

\author{
Mirian de L. O. e Silva ${ }^{2}$, Manoel A. de Faria ${ }^{2}$, Augusto R. de Morais ${ }^{2}$, Gustavo P. Andrade ${ }^{3}$ \& Elvis M. de C. Lima ${ }^{3}$
}

\section{RESUMO}

Neste trabalho se utilizaram dados experimentais obtidos na UFLA, no período de março a julho de 2004, com o objetivo de avaliar a produtividade de grãos e de óleo além de outras características agronômicas de dois genótipos de girassol (Helianthus annuus L.): $\mathrm{H} 250$ e H251, no período de entressafra; esses dados provieram de quatro experimentos conduzidos com tratamentos de lâminas de água referentes à reposição pela irrigação por gotejamento, de $0\left(\mathrm{~L}_{0}\right), 75\left(\mathrm{~L}_{1}\right)$, $100\left(L_{2}\right)$ e $130 \%\left(L_{3}\right)$ da evapotranspiração estimada para a cultura correspondendo, respectivamente, às lâminas de água de $117,20,350,84,428,70$ e 522,14 mm. A produtividade de grãos e de óleo, a altura das plantas e o diâmetro dos capítulos, aumentaram em função do aumento das lâminas de água, enquanto as cultivares utilizadas indicaram diferenças em relação aos fatores produtividade de óleo, peso de 1000 aquênios e altura de plantas. Notou-se eficiência técnica na produção, mesmo sem irrigação, com produtividade média de $1924,27 \mathrm{~kg} \mathrm{ha}^{-1}$ e, na condição irrigada, notaram-se aumentos significativos, chegando aos 2863,12 $\mathrm{kg} \mathrm{ha}^{-1}$ para a lâmina de 522,14 mm (130\% Etc) aplicada no ciclo da cultura. Os genótipos podem ser utilizados na entressafra, em Lavras, como opção na rotação de culturas.

Palavras-chave: oleaginosa, produtividade, irrigação

\section{Growth and productivity of sunflower cultivated in late summer and with different water depths}

\begin{abstract}
In this study the experimental data obtained in the period from March to July of 2004 in the Federal University of Lavras (UFLA) were used, with the objective of evaluating the productivity of grains and of oil and other agronomic characteristics of two sunflower genotypes (Helianthus annuus L.) (H250 and H251), irrigated in the late summer growth period. The experiment was carried out with four treatments of drip irrigation water depths of $0\left(\mathrm{~L}_{0}\right), 75\left(\mathrm{~L}_{1}\right), 100\left(\mathrm{~L}_{2}\right)$ and $130 \%\left(\mathrm{~L}_{3}\right)$ of the evapotranspiration estimated for the crop, corresponding, respectively, to the water depths of 117.20, 350.84, 428.70 and $522.14 \mathrm{~mm}$. The productivity of grains and of oil, the height of sunflower plants and the capitulum diameter increased with water depth. The used cultivars presented differences of oil productivity, weight of 1000 achene's and plants height. There was an technical efficiency in production, even without irrigation, with average productivity of 1924.27 kg ha-1 and, in irrigated condition, there was increase of this productivity reaching the $2863.12 \mathrm{~kg} \mathrm{ha}^{-1}$ for water depth of $522.14 \mathrm{~mm}(130 \% \mathrm{ETc})$ applied in the crop cycle. The analyzed genotypes can be used during the summer cycle, in Lavras, as an option in the crop rotation.
\end{abstract}

Key words: oleaginous, productivity, irrigation

1 Parte da tese de doutorado desenvolvida pela primeira autora

2 UFLA. Campus Universitário, CP 3037, CEP 37200-000, Lavras, MG. Fone: (35) 3829-1481. E-mail: misilva@ufla.br; mafaria@ufla.br; armorais@ufla.br

3 Graduandos em Engenharia Agrícola: gustavogold@uol.com.br; elviscastrolima@yahoo.com.br 


\section{INTRODUÇÃO}

O gênero Helianthus compreende 49 espécies e 19 subespécies, com 12 espécies anuais e 37 perenes, todas nativas das Américas (Ungaro,1990); por sua vez, o girassol comum (Helianthus annuus L.), que é a espécie cultivada mais importante do ponto de vista comercial, está entre as cinco maiores culturas oleaginosas produtoras de óleo vegetal comestível, sendo responsável por 6,5\% da produção mundial de oleaginosas na safra 2001/2002, ficando atrás apenas da soja, com 56,8\%; do algodão, com 11,3\%; da colza, com 11,1\% e do amendoim, com 10,23\% do total (Fagundes, 2002).

A produção mundial de girassol ficou, em 2004, em torno de 26.066 mil toneladas e os maiores produtores foram a Rússia, com 16,5\% da produção mundial, a Argentina, com 15,35\% e a União Européia, com 14,81\% (Agrianual, 2005).

O Brasil é um produtor pouco expressivo de grãos de girassol tendo participado com aproximadamente 0,5\% da produção mundial nos últimos anos (Fagundes, 2002); internamente, a produção de girassol se concentra nas regiões Centro-oeste (Goiás e Mato Grosso do Sul, com 45,6 e 23,8\%, respectivamente, da produção na safra 2004), Sul (Rio Grande do Sul, com 11,7\% da produção na safra 2004) e Sudeste (São Paulo, com 3,5\% da produção na safra 2004) (Agrianual, 2005). Esta produção cresceu de 56,3 mil toneladas em 2000 para 85,3 mil toneladas em 2004, assinalando um aumento de cerca de 52\%, enquanto neste mesmo período a área colhida aumentou de 37 mil para 54,7 mil hectares, representando um aumento de 48\% (Agrianual, 2005).

A demanda mundial por óleo de girassol vem crescendo, em média, 1,8\% ao ano mas no Brasil o crescimento foi de 5\%, em 2002. A demanda interna por óleo de girassol cresce, em média, $13 \%$ ao ano e, para suprir esta demanda, o País importa o óleo, principalmente da Argentina (Smiderle et al., 2005).

O girassol apresenta características desejáveis do ponto de vista agronômico, como ciclo curto, e alta qualidade e quantidade de óleo produzido, antevendo-se uma boa e nova opção de renda aos produtores brasileiros; esta possibilidade deverá ser aumentada com a recente decisão do governo Federal em se utilizar o biodiesel na matriz energética nacional, por meio de sua adição ao óleo diesel comercial.

Segundo Silva (1990) a região Sul do Estado de Minas Gerais é considerada, dentro da faixa de potencialidade climática para a cultura do girassol, apta para dois cultivos anuais complementares de girassol, no mesmo terreno.

No Sudeste, o cultivo do girassol em sucessão a grandes culturas, tem-se mostrado boa alternativa para o agricultor, permitindo o aproveitamento de áreas irrigadas ou não, na entressafra, e de reforma de canavial, na safra, ou mesmo áreas tradicionais (Gomes et al., 2003); ainda, o girassol, além de permitir a obtenção de grãos para produção de óleo na entressafra, pode diminuir a capacidade ociosa das indústrias, otimizando a utilização da terra, máquinas e mão-de-obra.

Pesquisadores têm comprovado em suas experimentações, que as melhores respostas obtidas de produtividade do gi- rassol associam a irrigação e adubação adequada, com ênfase ao fato de que a cultura é particularmente sensível a deficiência de boro (Ungaro, 1990). Com base nessas informações e dentre as várias tecnologias de produção de girassol, a escolha adequada de cultivares também é fundamental para se garantir o sucesso da cultura.

Em função do exposto torna-se justificável a preocupação com práticas culturais agronômicas para esta espécie vegetal no Brasil e, portanto se objetivou, através deste trabalho, estudar a viabilidade técnica de cultivo e o efeito de diferentes lâminas de irrigação sobre as características agronômicas e componentes de produção de duas cultivares de girassol, no período de entressafra, na região de Lavras, MG.

\section{MATERIAL E MÉTODOS}

Neste trabalho, se usaram dados experimentais conduzidos na Universidade Federal de Lavras (UFLA), localizada a $21^{\circ} 14^{\prime} 06^{\prime}$ " de latitude Sul e $45^{\circ} 00^{\prime} 00^{\prime \prime}$ de longitude Oeste, a uma média de $918 \mathrm{~m}$ de altitude (Castro Neto \& Silveira, 1983), no período de março a julho de 2004. A cidade de Lavras apresenta temperatura média diária de $19,4{ }^{\circ} \mathrm{C}$, precipitação total média anual de $1.529,7 \mathrm{~mm}$ de lâmina d’água e umidade relativa do ar média diária de 76,2\% (Brasil, 1992a); o solo da área experimental foi classificado como Latossolo Vermelho distroférrico, com textura muito argilosa, cujos dados resultantes da análise física estão apresentados na Tabela 1.

Tabela 1. Resultados da análise física do solo da área experimental, UFLA, Lavras,MG, $2005^{1}$

\begin{tabular}{|c|c|c|c|c|c|c|c|}
\hline \multirow{3}{*}{$\begin{array}{l}\text { Camada } \\
\text { (cm) }\end{array}$} & \multicolumn{3}{|c|}{ Análise textural } & \multirow[b]{2}{*}{$D_{g}$} & \multirow[b]{2}{*}{$D_{r}$} & \multirow[b]{2}{*}{ PMP } & \multirow[b]{2}{*}{ CC } \\
\hline & Areia & Limo & Argila & & & & \\
\hline & \multicolumn{3}{|c|}{$\left(\right.$ dag $\left.\mathrm{kg}^{-1}\right)$} & \multicolumn{2}{|c|}{$\left(\mathrm{g} \mathrm{cm}^{-3}\right)$} & \multicolumn{2}{|c|}{$\left(\mathrm{cm}^{3} \mathrm{~cm}^{-3}\right)$} \\
\hline $0-20$ & 9 & 44 & 47 & 1,01 & 2,74 & 0,28 & 0,37 \\
\hline $20-40$ & 9 & 18 & 73 & 1,00 & 2,70 & 0,28 & 0,41 \\
\hline
\end{tabular}

${ }_{1} D_{g}$ - densidade global, $D_{r}$ - densidade real, PMP - ponto de murcha permanente, CC - capacidade campo

Os dados aqui utilizados tiveram origem em quatro experimentos de lâminas de reposição de água $\left(\mathrm{L}_{\mathrm{i}}\right)$, aplicadas nas áreas efetivamente molhadas, resultantes da multiplicação da estimativa da evapotranspiração acumulada da cultura (ETc), entre dois dias de irrigação consecutivos, pelos fatores $0,75\left(\mathrm{~L}_{1}\right) ; 1,00\left(\mathrm{~L}_{2}\right)$ e $1,30\left(\mathrm{~L}_{3}\right)$ e a testemunha sem irrigação $\left(\mathrm{L}_{0}\right)$. Em cada experimento de lâmina de água procedeu-se à casualização dos demais tratamentos constituídos pelas combinações de três doses de boro e duas cultivares, de acordo com o esquema fatorial 3 x 2, utilizando-se o delineamento de blocos casualizados, com três repetições. As doses de boro empregadas foram $1,0 \mathrm{~kg} \mathrm{ha}^{-1}\left(\mathrm{~B}_{1}\right) ; 2,0 \mathrm{~kg} \mathrm{ha}^{-1}$ $\left(B_{2}\right)$ e $3,0 \mathrm{~kg} \mathrm{ha}^{-1}\left(B_{3}\right)$, aplicadas aos 25 dias após a emergência das plantas, junto com a primeira adubação de cobertura. Lançou-se mão de dois híbridos de girassol, Hélio 250 (H250) e Hélio 251 (H251), semeados em espaçamento de $0,8 \mathrm{~m}$ entre linhas, e densidade de 62500 plantas/ha. Cada unidade experimental com 5 linhas de plantio apresentou 
uma área de 12,16 m² e uma área útil com 3 linhas de plantio de $7,20 \mathrm{~m}^{2}$. Para a irrigação utilizaram-se gotejadores com vazão de $1,6 \mathrm{~L} \mathrm{~h}^{-1}$, espaçados $0,30 \mathrm{~m}$, formando uma faixa molhada contínua ao longo das linhas de plantio.

Os parâmetros climatológicos de evaporação e precipitação, obtidos diariamente junto à Estação Climatológica Principal de Lavras - INMET ( $5^{\circ}$ Distrito de meteorologia, Belo Horizonte, MG), localizada a $400 \mathrm{~m}$ da área experimental, foram avaliados e relacionados com o coeficiente de tanque Kt (FAO, 1979), a fim de se obter valores de ETo diários; a partir desses valores e dos coeficientes de cultura (Kc) nas diferentes fases de desenvolvimento da planta, estimou-se a evapotranspiração máxima da cultura (ETc), corrigida posteriormente pelo coeficiente de localização (Cabello, 1996). Os coeficientes de cultura utilizados foram os sugeridos pela FAO (1979).

A suspensão dos tratamentos de irrigação ocorreu aos 108 dias após a semeadura, cujo critério empregado foi o estádio de maturação fisiológica dos grãos, ou seja, quando os grãos estavam com massa dura.

Os dados analisados foram os de produtividade de grãos e de óleo, altura de plantas, diâmetros e área fecundada dos capítulos e peso de 1000 aquênios do girassol.

Após se definir as populações finais de plantas de girassol fez-se o acompanhamento do desenvolvimento fenológico da cultura através da observação de dez plantas localizadas nas linhas úteis de cada parcela. Os dados de altura de planta se basearam na medida de três plantas amostrais por parcela, na linha central, a cada 15 dias e a partir de 30 dias após a emergência.

Ao final do experimento correspondente à colheita (113 dias após a semeadura), os diâmetros externo e interno dos capítulos foram medidos, correspondentes ao círculo fertilizado e de posse desses dados, calculou-se a porcentagem da área fertilizada de dez plantas; na mesma época também foram calculados as produtividades de grãos e de óleo dos tratamentos e os pesos de 1000 aquênios, segundo Brasil (1992b).

Os dados coletados dos quatro experimentos foram primeiro analisados de forma individualmente através da análise de variância e, após verificação da possibilidade de realização da análise conjunta, esta foi feita e apresentada nesse trabalho. Os fatores que apresentaram diferença significativa pelo teste $\mathrm{F}$, foram posteriormente submetidos a uma análise de regressão em nível de 5\%.

\section{RESULTADOS E DISCUSSÃO}

Os valores referentes a $\mathrm{ETC}_{\mathrm{acum}}$, lâminas aplicadas durante a diferenciação dos tratamentos em cada mês, lâminas totais aplicadas em cada tratamento, e o total de água recebido pela cultura (irrigação + precipitação), são apresentados na Tabela 2.

Com base na escala fenológica proposta por Schneiter \& Miller (1981) acompanhou-se o desenvolvimento das plantas de girassol (Tabela 3), não se observando estresse climático sobre a duração dos períodos fenológicos estudados, de maneira que os resultados que seguem são devidos aos tratamentos aplicados. Salienta-se, porém, que houve precocidade do híbrido H250, por ocasião dos períodos fenológicos estudados, com diferença de cinco dias.

Os resumos da análise de variância para todas as características estudadas se encontram na Tabela 4.

Analisando-se o comportamento da altura de plantas de girassol notou-se um aumento relativo referente às plantas, em função da lâmina de água aplicada (Figura 1A), em que a lâmina que proporcionou maior crescimento foi $522,14 \mathrm{~mm}$.

Tabela 2. Estimativa da evapotranspiração acumulada da cultura $\left(E_{\text {acum }}\right)$, precipitação, lâminas de irrigação $\left(\mathrm{L}_{1}, \mathrm{~L}_{2}\right.$ e $\left.\mathrm{L}_{3}\right)$ e total de água recebida pela cultura, em $\mathrm{mm}$, durante a diferenciação dos tratamentos de irrigação, UFLA, Lavras, MG, 2005

\begin{tabular}{|c|c|c|c|c|c|}
\hline \multirow{2}{*}{ Período } & $\mathrm{ETc}_{\text {acum }}$ & $\mathrm{L}_{0}$ & $\mathrm{~L}_{1}$ & $\mathrm{~L}_{2}$ & $\mathrm{~L}_{3}$ \\
\hline & \multicolumn{5}{|c|}{$(\mathrm{mm})$} \\
\hline Abril (4 dias) & 20,80 & - & 15,60 & 20,80 & 27,04 \\
\hline Maio (31 dias) & 99,98 & - & 74,99 & 99,98 & 129,97 \\
\hline Junho (30 dias) & 142,94 & - & 107,21 & 142,94 & 185,82 \\
\hline Julho (7 dias) & 47,78 & - & 35,84 & 47,78 & 62,11 \\
\hline $\mathrm{ETC}_{\text {acum }}$ Total & 311,50 & & & & \\
\hline \multicolumn{2}{|c|}{ Total de água aplicada } & 0,00 & 233,64 & 311,50 & 404,94 \\
\hline \multicolumn{6}{|c|}{ Precipitação durante a diferenciação dos tratamentos $=117,2 \mathrm{~mm}$} \\
\hline \multicolumn{2}{|c|}{ Total irrig. + precipitação } & 117,20 & 350,84 & 428,70 & 522,14 \\
\hline
\end{tabular}

Tabela 3. Duração, em dias após a emergência, de diferentes períodos fenológicos de duas cultivares de girassol. UFLA, Lavras, MG, 2005

\begin{tabular}{|c|c|c|c|c|c|}
\hline \multirow{3}{*}{ Cultivares } & \multicolumn{5}{|c|}{ Período fenológico ${ }^{1}$} \\
\hline & $\mathbf{R}_{3}$ & $\mathbf{R}_{5.1}$ & $\mathbf{R}_{5.5}$ & $\mathbf{R}_{6}$ & $\mathbf{R}_{\mathbf{9}}$ \\
\hline & \multicolumn{5}{|c|}{ Dias após a emergência } \\
\hline H251 & 30 & 55 & 70 & 90 & 105 \\
\hline $\mathrm{H} 250$ & 30 & 50 & 65 & 85 & 100 \\
\hline
\end{tabular}

${ }^{1} R_{3}$ - botão floral formado; $R_{5.1}$ - início da ântese; $R_{5.5}$ - metade da ântese; $R_{6}$ - ântese completa; $\mathrm{R}_{9}$ - maturação

Castiglioni et al. (1993), em Londrina, PR, avaliando 17 genótipos de girassol, todos diferentes dos híbridos utilizados neste trabalho, notaram que o aumento no suprimento de água incrementava o parâmetro altura de plantas.

O experimento ora conduzido proporcionou incrementos médios na altura de plantas, da ordem de 16,41, 15,63 e $18,75 \%$ (Tabela 5) nos tratamentos irrigados $\mathrm{L}_{1}(350,84 \mathrm{~mm})$, $\mathrm{L}_{2}(428,70 \mathrm{~mm})$ e $\mathrm{L}_{3}(522,14 \mathrm{~mm})$, respectivamente, comparados com o tratamento não irrigado $\mathrm{L}_{0}(117,20 \mathrm{~mm})$. Concordando com esta informação, Castro (1999) compara plantas de girassol submetidas e não submetidas em todo o ciclo da cultura, ao estresse hídrico, encontrando incrementos na altura de plantas da ordem de $24,42 \%$ para os tratamentos sem estresse hídrico.

Os incrementos encontrados neste estudo também foram semelhantes aos de Gomes et al. (2003) que, ao estudarem plantas de girassol submetidas a irrigação segundo balanço hídrico no solo e plantas sem suplementação hídrica, encontraram incrementos na altura de plantas, da ordem de 29,30\%, 
Tabela 4. Resumos da análise de variância para as características altura de plantas $\left(A_{p}\right)$, diâmetro externo de capítulos $\left(D_{\text {ext }}\right)$ \% de área fecundada dos capítulos $\left(\mathrm{A}_{\mathrm{f}}\right)$, peso de 1000 aquênios $\left(\mathrm{P}_{1000}\right)$, produtividades de grãos $\left(\mathrm{P}_{\mathrm{g}}\right)$ e de óleo $\left(\mathrm{P}_{\mathrm{o}}\right)$ das plantas de girassol, UFLA, Lavras, $M G, 2005^{1}$

\begin{tabular}{|c|c|c|c|c|c|c|c|}
\hline \multirow{2}{*}{ Fonte de Variação } & \multirow{2}{*}{ GL } & \multicolumn{6}{|c|}{ Quadrado Médio } \\
\hline & & $A_{p}$ & $D_{\text {ext }}$ & $A_{f}^{2}$ & $P_{1000}$ & $P_{g}$ & $P_{0}$ \\
\hline $\mathrm{L}$ & 3 & $1,044^{*}$ & $11,51^{*}$ & $48,35^{\star}$ & $6,06^{\mathrm{ns}}$ & $2872128,39 *$ & $212514,45^{*}$ \\
\hline $\mathrm{R} 1$ & 8 & 0,137 & $1,39^{\text {ns }}$ & 11,32 & 8,38 & 548853,81 & 28767,13 \\
\hline$B$ & 2 & $0,001^{\text {ns }}$ & $0,79^{n s}$ & $19,50^{\mathrm{ns}}$ & $2,60^{\mathrm{ns}}$ & $105412,52^{\mathrm{ns}}$ & $28738,77^{\text {ns }}$ \\
\hline C & 1 & $4,015^{\star}$ & $8,75^{\text {ns }}$ & $3,64^{\mathrm{ns}}$ & $552,56^{*}$ & $552066,50^{\mathrm{ns}}$ & $691850,45^{*}$ \\
\hline$B \times C$ & 2 & $0,035^{\mathrm{ns}}$ & $3,18^{\mathrm{ns}}$ & $3,57^{\mathrm{ns}}$ & $15,79^{\text {ns }}$ & $264683,42^{\mathrm{ns}}$ & $13578,04^{\mathrm{ns}}$ \\
\hline$L \times C$ & 3 & $0,036^{\mathrm{ns}}$ & $1,49^{\mathrm{ns}}$ & $4,47^{\mathrm{ns}}$ & $19,54^{\mathrm{ns}}$ & $605954,49^{n s}$ & $41769,64^{\mathrm{ns}}$ \\
\hline$L \times B \times C$ & 6 & $0,016^{\mathrm{ns}}$ & $1,82^{\mathrm{ns}}$ & $9,96^{\mathrm{ns}}$ & $8,19^{\text {ns }}$ & $211661,60^{\text {ns }}$ & $30415,95^{\text {ns }}$ \\
\hline $\mathrm{R} 2$ & 40 & 0,033 & 2,99 & 8,76 & 7,00 & 366219,38 & 21282,09 \\
\hline Total & 71 & & & & & & \\
\hline Média geral & & 1,44 & 17,28 & 64,49 & 38,38 & 2411,20 & 565,44 \\
\hline CV1 (\%) & & 25,60 & 6,82 & 5,22 & 7,55 & 30,73 & 30,00 \\
\hline CV2 (\%) & & 12,65 & 10,02 & 4,59 & 6,90 & 25,10 & 25,80 \\
\hline
\end{tabular}

${ }^{1} \mathrm{~L}$ - lâminas; R1 - resíduo 1; B - boro; C - cultivar; ns - não significativo; * - significativo a $5 \%$ de probabilidade

${ }^{2}$ Os dados foram submetidos a transformação $\operatorname{arcsen} \sqrt{x / 100}$

A.

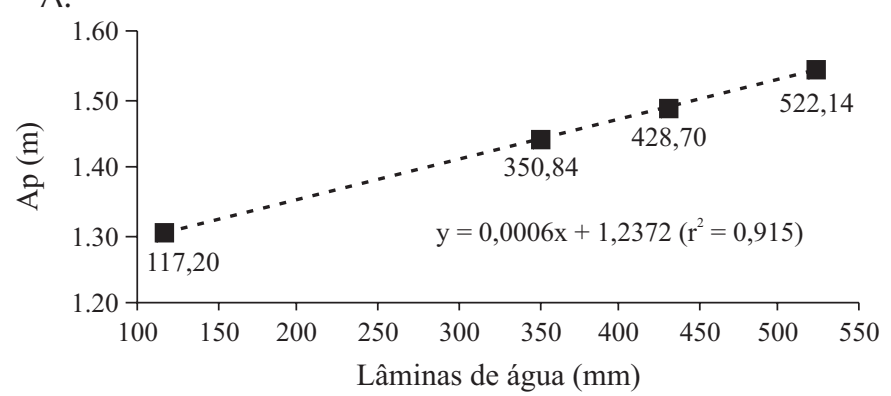

C.

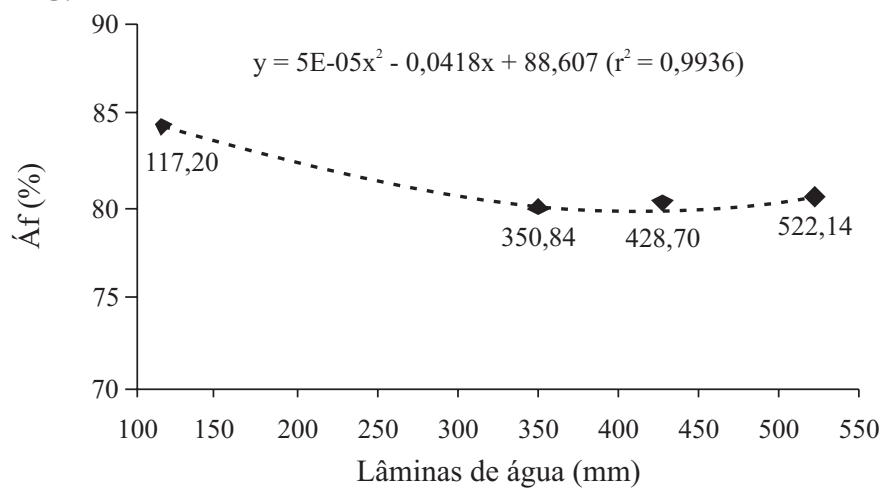

E.

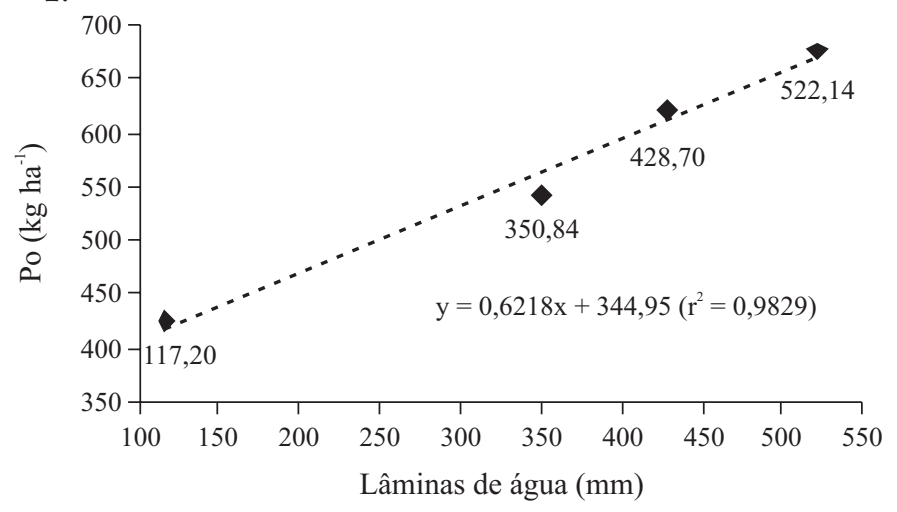

B.

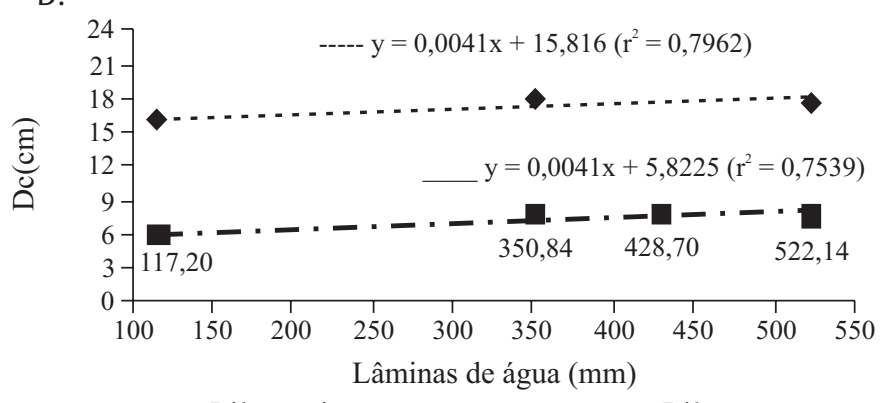

D.

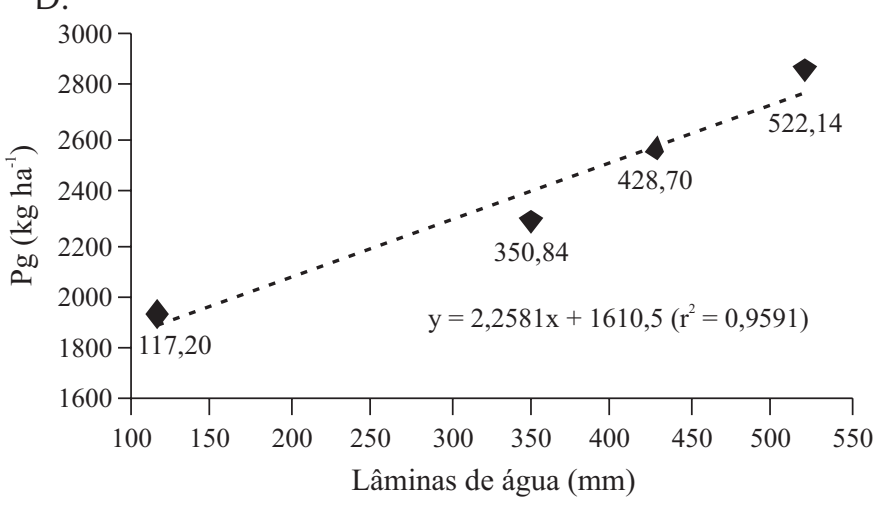

Figura 1. Representação gráfica e equação de regressão da altura (A), diâmetros (B) e área fecundada (C) dos capítulos, produtividades de grãos (D) e óleo (E) das plantas de girassol, em função das lâminas de água. UFLA, Lavras, MG, 2005 
Tabela 5. Médias das alturas de plantas $\left(A_{p}\right)$, dos diâmetros externos $\left(D_{\text {ext }}\right)$ e da área fertilizada $\left(A_{\mathrm{f}}\right)$ dos capítulos das plantas de girassol, e das produtividades de grãos $\left(\mathrm{P}_{\mathrm{g}}\right)$ e de óleo $\left(\mathrm{P}_{0}\right)$ dos grãos de girassol em função das lâminas de água (L). UFLA, Lavras, MG, 2005

\begin{tabular}{cccccc}
\hline $\begin{array}{c}\text { Lâminas } \\
(\mathbf{m m})\end{array}$ & $\begin{array}{c}\mathbf{A}_{\mathbf{p}} \\
(\mathbf{m})\end{array}$ & $\begin{array}{c}\mathbf{D}_{\text {ext }} \\
(\mathbf{c m})\end{array}$ & $\begin{array}{c}\mathbf{A}_{\mathbf{f}} \\
(\mathbf{\%})\end{array}$ & $\begin{array}{c}\mathbf{P}_{\mathbf{g}} \\
\left.\mathbf{( k g ~ h a}^{-1}\right)\end{array}$ & $\begin{array}{c}\mathbf{P}_{\mathbf{0}} \\
\left(\mathbf{k g ~ h a}^{-1}\right)\end{array}$ \\
\hline 117,20 & 1,28 & 16,081 & 66,940 & 1924,27 & 424,94 \\
350,84 & 1,49 & 17,747 & 63,508 & 2293,15 & 541,34 \\
428,70 & 1,48 & 17,639 & 63,632 & 2564,26 & 619,92 \\
\hline 522,14 & 1,51 & 17,644 & 63,895 & 2863,12 & 675,57 \\
\hline
\end{tabular}

para os tratamentos irrigados. Através da ANOVA (Tabela 4), também se verificaram, diferenças significativas entre as cultivares com relação à altura de plantas de girassol com maiores valores (1,55 m) para a cultivar H251 (Tabela 6), independente dos outros fatores considerados, levando a crer que esta diferença ocorra em função apenas do fator genético. Silva et al. (2005b), Lemos \& Vazquez (2005) e Leite \& Carvalho (2005) trabalhando com o cultivar H250 de girassol, no período da safrinha e sem irrigação, em Lucianópolis, Fernandópolis, SP, e Londrina, PR, encontraram alturas médias de plantas de 1,03, 1,24 e 2,00 m, respectivamente; por outro lado, Lemos \& Vazquez (2005), Silva et al (2005b), e Leite \& Carvalho (2005), trabalhando com a cultivar H251 de girassol, no período de safrinha e sem irrigação, em Fernandópolis, SP, Rio Verde, GO, e Londrina, PR, constataram alturas médias de plantas de 1,49, 0,96, 1,69 $\mathrm{m}$, respectivamente.

Tabela 6. Médias das alturas de plantas $\left(A_{p}\right)$, produtividade de óleo nos aquênios $\left(\mathrm{P}_{0}\right)$ e peso de mil aquênios (P1000) de duas cultivares de girassol. UFLA, Lavras, MG, 2005

\begin{tabular}{cccc}
\hline Cultivares & $\mathbf{A}_{\mathbf{p}}(\mathbf{m})$ & $\left.\mathbf{P}_{\mathbf{0}} \mathbf{~ k g ~ h a ~}^{-1}\right)$ & $\mathbf{P}_{\mathbf{1 0 0 0}} \mathbf{( g )}$ \\
H250 & 1,339 & 663,47 & 41,15 \\
H251 & 1,550 & 467,42 & 35,61 \\
\hline
\end{tabular}

Quanto ao diâmetro externo e interno dos capítulos em função da lâmina de água aplicada (Figura 1B), a lâmina $\mathrm{L}_{3}$ (522,14 mm) proporcionou maior tamanho aos capítulos das plantas de girassol. O incremento médio observado nos tratamentos irrigados foi da ordem de 9,93\%, comparados ao tratamento não irrigado, como mostra a Tabela 5; esses resultados são concordantes com os obtidos por Gomes et al. (2003) que também constataram menores diâmetros nos tratamentos não irrigados. Silva et al. (2005a, b), trabalhando com as cultivares H250 e H251 de girassol, no período de safrinha e sem irrigação, em Lucianópolis, SP, e Rio Verde, GO, notaram diâmetros médios dos capítulos das plantas de 14,45 e 12,2 cm, respectivamente. Comparando os resultados com o obtido neste estudo, verifica-se a possibilidade de obtenção de maior produção de grãos em função de maiores tamanhos médios de capítulos encontrados, ou seja, 16,93 e $17,63 \mathrm{~cm}$, respectivamente.

Com os resultados dos diâmetros externos e internos dos capítulos das plantas de girassol, analisou-se a porcentagem de sua área fecundada, ou seja, a área potencialmente capaz de produzir grãos e se observaram decréscimos da porcenta- gem desta área em função do aumento das lâminas de água aplicadas, conforme mostra a Figura 1C, com incremento médio da ordem de 5\% no tratamento não irrigado quando comparado com a média dos tratamentos irrigados (Tabela 5).

Este resultado não afetou significativamente a produção final de grãos visto que o decréscimo ocorreu na área relativa do capítulo mas não na área fecundada, uma vez que esta cresceu com o aumento da irrigação, proporcionando maior produtividade para os tratamentos irrigados, com acréscimos em função das lâminas de água aplicadas.

Com relação à produtividade de grãos de girassol em $\mathrm{kg} \mathrm{ha}^{-1}$, foi notório o seu aumento relativo em função das lâminas de água aplicadas (Figura 1D) sendo que, para a lâmina $\mathrm{L}_{3}(522,14 \mathrm{~mm})$ a produtividade chegou a 2863,12 $\mathrm{kg} \mathrm{ha}^{-1}$.

Verificou-se um incremento médio da ordem de 19,17, 33,26 e 48,79\% para os tratamentos irrigados $\mathrm{L}_{1}, \mathrm{~L}_{2}$ e $\mathrm{L}_{3}$, respectivamente, quando comparados com o tratamento não irrigado $\mathrm{L}_{0}$ (Tabela 5). Esses incrementos foram similares aos encontrados por Gomes et al. (2003 e 2005). Resultados similares também foram apresentados por Andrade (2000), em Jaboticabal, SP, quando utilizou 100\% de reposição da ETc.

Lemos \& Vazquez (2005), trabalhando com os híbridos H250 e H251 de girassol, no período de safrinha e sem irrigação, em Fernandópolis, SP, notaram produtividades médias de grãos de 2828,7 e 1050,8 $\mathrm{kg} \mathrm{ha}^{-1}$, respectivamente; já, em Londrina, PR, para Leite \& Carvalho (2005), essas produtividades médias de grãos foram de 1682 e $1839 \mathrm{~kg} \mathrm{ha}^{-1}$, respectivamente, para os híbridos H250 e H251 e Silva et al. (2005a, b), produtividades médias de 2000 e $1056 \mathrm{~kg} \mathrm{ha}^{-1}$, respectivamente, no período de safrinha e sem irrigação, em Lucianópolis, SP, e Rio Verde, GO, respectivamente.

Com relação à produtividade de óleo dos grãos de girassol, o aumento foi relativo em função das lâminas de água aplicadas (Figura 1E), embora para a lâmina $\mathrm{L}_{3}$ (522,14 mm) a produtividade de óleo dos grãos tenha chegado a $675,57 \mathrm{~kg} \mathrm{ha}^{-1}$ além de incremento médio da ordem de 34,65 , 46,36 e 60,30\% para os tratamentos irrigados $L_{1}$, $\mathrm{L}_{2}$ e $\mathrm{L}_{3}$, respectivamente, quando comparados com o tratamento não irrigado, $\mathrm{L}_{0}$ (Tabela 5).

Ao se analisar a produtividade de óleo (Figura 1E), vê-se que ela apresentou comportamento semelhante ao ocorrido com a produtividade de grãos (Figura 1D); desta forma, percebe-se que o fator mais significativo para a produtividade de óleo na cultura do girassol foi, além do teor inerente à semente, a produtividade de grãos, caracterizando a importância da disponibilidade hídrica em períodos críticos de desenvolvimento da cultura; este comportamento foi semelhante aos resultados obtidos por Castro (1999).

Constatou-se maior produtividade de óleo nos grãos para a cultivar H250 (663,47 $\left.\mathrm{kg} \mathrm{ha}^{-1}\right)$, com aumento médio de 42\% quando comparado com a cultivar H251 (467,42 kg ha-1) (Tabela 6).

Em Dourados, MS, trabalhando em diversos genótipos de girassol, Endres (1993) encontrou produtividade média de óleo nos aquênios em torno de $630 \mathrm{~kg} \mathrm{ha}^{-1}$, próxima à produtividade mostrada neste trabalho para a cultivar H250; também Carvalho et al. (2003) trabalhando com 
outros genótipos de girassol na região Sudeste do Brasil, encontraram produtividades médias de óleo nos aquênios próxima à produtividade indicada no presente estudo, para a cultivar H250; já EMBRAPA (2003a, b), lidando com os híbridos H250 e H251, encontrou maiores valores médios de produtividade de óleo por hectare quando comparados com os valores obtidos no presente estudo.

Com relação ao peso de 1000 sementes a cultivar H250 apresentou maior peso (41,15 g), mesmo não o fazendo quanto a diferenças significativas com relação à produtividade de grãos $\left(\mathrm{kg} \mathrm{ha}^{-1}\right)$ e ao diâmetro de capítulos $(\mathrm{cm})$. O teor (\%) e a produtividade $\left(\mathrm{kg} \mathrm{ha}^{-1}\right)$ de óleo permaneceram superiores para esta cultivar (Tabela 6).

Os valores de pesos de 1000 aquênios, indicados neste trabalho, foram inferiores aos encontrados por Lemos \& Vazquez (2005) e Silva et al. (2005b), trabalhando com os híbridos H250 e H251 de girassol, fato este que pode estar associado ao baixo valor de óleo e à maior quantidade de fibras encontrados nas sementes deste estudo; por sua vez, os resultados apresentados para peso de 1000 aquênios do estudo, foram semelhantes aos apresentados por Leite \& Carvalho (2005); trabalhando com outros genótipos de girassol Bevitori (1993) e Castiglioni et al. (1993) encontraram valores de peso de 1000 aquênios coincidentes com a faixa de valores indicados neste estudo.

\section{CONCLUSÕES}

1. A irrigação proporcionou aumento na produtividade de grãos e de óleo e na altura das plantas de girassol, sendo a lâmina de 522,14 mm a que proporcionou melhor resposta.

2. Notou-se eficiência técnica na produção uma vez que, mesmo sem irrigação, a produtividade média foi de $1924,27 \mathrm{~kg} \mathrm{ha}^{-1}$; todavia, em condições irrigadas, deu-se aumento desta produtividade chegando aos 2863,12 kg ha-1 para a lâmina de 522,14 mm.

3. A cultivar H250 apresentou melhor resposta com relação à produtividade de óleo e peso de mil aquênios.

4. Não houve influência da dosagem de boro nas características avaliadas.

\section{LITERATURA CITADA}

Agrianual - Anuário da Agricultura Brasileira. São Paulo: FNP Consultoria e Comércio, 2005. 520p.

Andrade, S. J. de. Efeito de lâminas de água e doses de boro na cultura do girassol. Piracicaba: ESALQ/USP, 2000.94p. Tese Doutorado

Bevitori, R. Avaliação de cultivares de girassol em Goiânia-Janeiro/93. In: Reunião Nacional de Girassol, 10., 1993, Goiânia. Resumos... Goiânia: IAC, 1993. p.33.

Brasil. Ministério da Agricultura e Reforma Agrária. Normais Climatológicas 1961-1990. Brasília, 1992a. 84p.
Brasil. Ministério da Agricultura e Reforma Agrária. Regras para análise de sementes. Brasília: SNDA; DNDA; CLAV, 1992b. 365p.

Cabello, F. P. Riegos localizados de alta freqüência (RLAF) Goteo, microaspersion, exudacion. 3.ed. Barcelona: Mundi Prensa, 1996.513p.

Carvalho, C. G. P. de; Oliveira, M. F. de; Castiglioni, V. B. R.; Leite, R. M. V. B. de C.; Vieira, O. V. Desempenho produtivo de genótipos de girassol em diferentes regiões do Brasil nas safras 2001/2002 e 2002. In: Simpósio Nacional de Girassol, 3, e Reunião Nacional da Cultura de Girassol, 15, 2003, Ribeirão Preto. Anais... Ribeirão Preto: CATI, 2003, CD-Rom

Castiglioni, V. B. R.; Castro, C.; Balla, A. Avaliação de genótipos de girassol em ensaio intermediário (1992/93), LondrinaPR. In: Reunião Nacional de Girassol, 10, 1993, Goiânia. Resumos... Goiânia: IAC, 1993. p.37.

Castro, C. de. Boro e estresse hídrico na nutrição e produção do girassol em casa-de-vegetação. Piracicaba: ESALQ/USP, 1999. 120p. Tese Doutorado

Castro Neto, P.; Silveira, J. V. Precipitação provável para Lavras, MG, baseada na função de distribuição de probabilidade gama III. Períodos de 10 dias. Ciência e Prática, Lavras, v.7, n.1, p.58-65, 1983.

EMBRAPA - Empresa Brasileira de Pesquisa Agropecuária. Centro Nacional de Pesquisa de Soja. Informes da avaliação de genótipos de girassol 2001/2002 e 2002. Londrina: EmbrapaCNPSo, 2003a. 97p. Documentos 226

EMBRAPA - Empresa Brasileira de Pesquisa Agropecuária. Centro Nacional de Pesquisa de Soja. Informes da avaliação de genótipos de girassol 2002/2003 e 2003. Londrina: EmbrapaCNPSo, 2003b. 87p. Documentos 205

Endres, V. C. Avaliação de cultivares de girassol no Mato Grosso do Sul. In: Reunião Nacional de Girassol, 10, 1993, Goiânia. Resumos... Goiânia: IAC, 1993. p.35.

Fagundes, M. H. Sementes de girassol: Alguns comentários. http:/ www.conab.gov.br. 5 Out. 2002.

FAO. Production yearbook. Rome: FAO, 1979, v.33.

Gomes, E. M.; Ungaro, M. R. G.; Vieira, D. B. Impacto da suplementação hídrica no acúmulo e partição da matéria seca de girassol. In: Simpósio Nacional de Girassol, 3, e Reunião Nacional da Cultura de Girassol, 15, 2003, Ribeirão Preto. Anais... Ribeirão Preto: CATI, 2003., CD-Rom

Gomes, E. M.; Ungaro, M. R. G.; Vieira, D. B. Produção de grãos, óleo e proteína em girassol sob estresse hídrico. In: Simpósio Nacional de Girassol, 4.; Reunião Nacional da Cultura de Girassol, 16., 2005, Londrina. Anais... Londrina: Embrapa/Soja, 2005. p.23-25.

Leite, R. M. V. B. C.; Carvalho, C. G. P. Avaliação da resistência de genótipos de girassol à mancha de Alternaria (Alternaria helianthi) em condições de campo. In: Reunião Nacional de Pesquisa de Girassol, 16, e Simpósio Nacional sobre a Cultura do Girassol, 4, 2005, Londrina. Anais... Londrina: Embrapa Soja, 2005. p.108-110.

Lemos, D. M. R.; Vazquez, G. H. Comportamento agronômico de diferentes genótipos de girassol na época da safrinha em Fernandópolis/SP. In: Reunião Nacional de Pesquisa de Girassol, 16, e Simpósio Nacional sobre a Cultura do Girassol, 4, 2005, Londrina. Anais... Londrina: Embrapa Soja, 2005. p.76-79.

R. Bras. Eng. Agríc. Ambiental, v.11, n.5, p.482-488, 2007. 
Schneiter, A. A.; Miller, J. F. Description of sunflower growth stages. Crop Science, v.21, n.6, p.901-903, 1981.

Silva, A. G. da; Moraes, E. B. de; Pires, R.; Carvalho, C. G. P. de; Oliveira, A. C. B. de. Efeito do espaçamento entre linhas em três híbridos de girassol. In: Reunião Nacional de Pesquisa de Girassol, 16, e Simpósio Nacional sobre a Cultura do GirassoL, 4, 2005a, Londrina. Anais... Londrina: Embrapa Soja, 2005. p.86-88.

Silva, M. N. da. A cultura do girassol. Jaboticabal: FUNEPUNESP, 1990.67p.

Silva, M. R.; Ungaro, M. R. G.; Ramos, N. P.; Aguiar, R. H. Cultivo de girassol em Lucianópolis - Estudo de caso In: Reunião
Nacional de Pesquisa de Girassol, 16, e Simpósio Nacional sobre a Cultura do Girassol, 4, 2005, Londrina. Anais... Londrina: Embrapa Soja, 2005b. p.68-70.

Smiderle, O. J.; Mourão Júnior, M.; Gianluppi, D.; Castro, C. de. Adubação nitrogenada para girassol nos cerrados de Roraima. In: Reunião Nacional de Pesquisa de Girassol, 16, e Simpósio Nacional sobre a Cultura do Girassol, 4, 2005, Londrina. Anais... Londrina: Embrapa Soja, 2005. p.32-35.

Ungaro, M. R. G. Girassol (Helianthus annuus L.). In: Boletim Informativo do Instituto Agronômico, Campinas, v.200, n.5, p.112-113, 1990. 